\title{
Surety Bonds with Fair and Unfair Pricing
}

\begin{abstract}
Achim Wambach ${ }^{\mathrm{a}}$ and Andreas R. Engel ${ }^{\mathrm{b}}$
${ }^{a}$ Department of Economics, University of Cologne, Albertus Magnus Platz, Koeln D-50931, Germany.

E-mail: wambach@wiso.uni-koeln.de

${ }^{\mathrm{b}}$ TWS Partners, Widenmayerstr. 38, D-80538 Muenchen, Germany.

Surety bonds are instruments used in public and private procurement to avoid the problem of contractor bankruptcy. A surety company issuing such a bond guarantees to either finish the project itself or pay the bond to the procurement agency in case of contractor's bankruptcy. This situation is analysed under the assumption that the bond is either priced fairly, or a risk loading that is proportional to the money at risk is imposed. If the surety is priced fairly, full insurance (or even overinsurance) is optimal. If the surety is priced unfairly, more solvent contractors are more likely to win, thus the problem of abnormally low tenders is alleviated.

The Geneva Risk and Insurance Review (2011) 36, 36-50. doi:10.1057/grir.2010.8; published online 11 May 2010
\end{abstract}

Keywords: auctions; bankruptcy; limited liability; surety bonds

\section{Introduction}

During a procurement process, a low winning tender can be bad news for the procurement agency if the project leads to financial distress of the winning contractor who could go bankrupt before finishing the project. Of the 850,000 contractors in business in the United States in 2004, only 650,000 were still in business in 2006; a failure rate of 23.6 per cent. ${ }^{1}$ Contractor bankruptcy can be very costly for the agency: the direct costs of bankruptcy (e.g., lawyers) make up 7-20 per cent of the liquidation proceeds and the indirect costs (e.g., delays) are estimated to be even higher (White, 1989). To be more specific, the 80,000 contractors that went bankrupt in the U.S. construction industry between 1990 and 1997 left unfinished construction projects with liabilities exceeding U.S.\$ 21 billion. $^{2}$

\footnotetext{
${ }^{1}$ For more details of the U.S. surety market see Ramsey (2008).

${ }^{2}$ Dun and Bradstreet Business Failure Record, cited from Calveras et al. (2004).
} 
To deal with the problem of bankrupt contractors, several governments introduced surety bonds in public procurement (among others Brazil, Canada, Italy, Japan, and the U.S.A.). In the U.S.A. the federal Miller Act requires a surety bond from all construction contractors if the value of the project exceeds U.S.\$ $100.000 .^{3}$ Surety bonds are used as well in the private sector . For instance, 17 per cent of the surety bonds in the U.S.A. (Russell, 1999, p. 4) were accounted for by private agencies. The U.S. practice uses two kinds of bonds, a performance bond and a payment bond. We focus our analysis on the performance bond whose size is usually 100 per cent of the project value and protects the agency from financial loss if the contractor fails to fulfil the contract. ${ }^{4}$ Surety bonds are issued by surety and insurance companies that are approved by the U.S. Treasury. In contrast to most insurance contracts or letters of credit, surety bonds are not designed to cover the expected loss in case of failure but to avoid failure. This is done by screening the project's risks (inherent risk, type of coverage, etc.) as well as the contractor's risks (tangible assets, past performance, etc. $)^{5}$ and charging a risk-adjusted insurance premium. Premia in the U.S. vary between 0.5 per cent and 3 per cent of the project value (source: www.sio.org) and are derived from rate manuals issued by the Surety \& Fidelity Association of America and by surety companies or are individually adjusted by surety companies. The rates are usually percentage shares of the project value that decrease in project value. In the case of failure, the surety company guarantees either to finish the project or to abandon the project and pay the surety bond to the agency. ${ }^{6}$

Surety bonds were recently analysed by Calveras, Ganuza, and Hauk $(\mathrm{CGH}$, 2004). CGH show that surety companies that are specialized in screening the contractors can help to mitigate the problem of contractors going bankrupt. They also show that the U.S. practice of requiring a bond whose size is equal to the actual payment may lead to inefficient overinsurance. $\mathrm{CGH}$ derive their results under the assumption that if a surety bond of size $L$ is required from the contractor, the issuing surety company has to freeze $L$ and has opportunity costs of $r L$, which is the return of a risk-free investment.

${ }^{3}$ Many states in the U.S. have adopted the Miller Act (www.sio.org). The issue was on the agenda in the EU as well. In 1999, the European Commission's Enterprise Section published a report titled "Abnormally low tenders" (ALT) with detection and rejection rules for ALTs and started a working group on surety bonds (European Commission Enterprise Section, 1999). However, no further procedures regarding surety bonds in the EU were recommended.

${ }^{4}$ The payment bond ensures that the contractor will pay subcontractors, workers, etc.

${ }^{5}$ Contractors are usually divided into three broad classes that have direct influence on the premium: intermediate, merit, and preferred. For examples, see Russell (1999, p. 97).

${ }^{6}$ The U.S. surety industry had to cover failure losses of $\$ 1,3$ billion from 1995 to 2005 (source: www.sio.org). 
We base our analysis on the framework introduced by CGH but modify their pricing assumption. This is done for three reasons: first, the insurance literature has always focused on the benchmark of fair insurance in which an efficient outcome is obtained. Thus it is interesting to analyse fairly priced surety bonds and the resulting outcome in the present context. Second, even if insurance is priced unfairly, the risk loading should be related to the money at risk and not to the size of the payment. For example, in case the contractor never goes bankrupt (i.e., owns enough financial assets), the surety company knows that the contractor's assets (and therefore the project) are not at risk and should not charge a risk premium. Third, even if a surety bond of size $L$ has to be frozen to cover the potential loss, it can be invested. In contrast to CGH we assume that the bond can be invested at some risk-free interest rate that is the same for all surety companies.

We obtain the following new results compared to CGH: With fair pricing, the problem becomes analytically solvable. The optimal fairly priced surety bond is such that finishing the project is always preferred. Furthermore, overinsurance in the sense that the surety bond required is higher than the money at risk can be efficient. This result is not at odds with the insurance literature (where fair pricing leads to full insurance), as overinsurance on the side of the agency translates into full insurance on the side of the surety company since it implies that the surety company will always finish the project.

If insurance is priced marginally unfair, with pricing being proportional to the money at risk, the bidding behaviour of the contractors might become nonmonotonic or even decrease in wealth. This can be understood by noting that although low wealth contractors bid more aggressively as they have less to lose in case of bankruptcy, due to unfair pricing these contractors have to pay a higher risk loading. Thus surety bonds help to alleviate the problem of abnormally low tenders (ALTs) as contractors who are more likely to go bankrupt end up submitting higher bids than more solvent contractors.

If the unfair component of the pricing scheme is proportional to the money at risk, overinsurance might still be optimal if bankruptcy costs are high. The intuition is the following: the agency wants to protect itself against the trouble that arises if the contractor goes bankrupt, while surety bonds cover the costs of finishing the project. As CGH already observed, if the inconveniences for the agency are large compared to the costs of finishing the project in case of bankruptcy, then the agency prefers to become fully insured even under unfair pricing. Overinsurance will then also be optimal because any amount of insurance beyond the necessary does not come with an additional risk loading. However, this only holds if the price is proportional to the money at risk and not to the size of the surety bond.

The results concerning the optimal size of surety bonds have consequences for the U.S. practice, which requires surety bonds whose size is equal to the 
project payment. It could be argued that this size is larger than the money at risk, as for example contractors have some financial means such that in case of bankruptcy not the whole project is forfeited. This paper shows that this form of insurance does not imply inefficient overinsurance but might indeed be optimal, as long as pricing is either fair or the loading is related to the risk of the surety bond.

This paper contributes to the recent literature on ALTs and auctions with bidders with limited liability. Parlane (2003) and Board (2007) show that bidders with limited liability bid more aggressively as their downside risk is cut off. While they analyse classic auction formats and the general mechanism, Engel and Wambach (2006) compare how several commonly used procurement methods - beyond the standard auctions - perform in the context of limited liability. In a common-value selling auction, Zheng (2001) shows that if bidders are budget constrained, the value of the object auctioned is uncertain, and the payment can be postponed, the most budget-constrained bidder is most likely to win the auction. An overview of this literature is given in Engel et al. (2006).

The paper is structured as follows: in the second section, we set up the model. In the third section the bidding strategy and the size of the optimal surety bond for fair insurance pricing is determined. In the fourth section, we derive properties of the bidding strategy and discuss the optimal size of the surety bond for unfair premia. The last section concludes.

\section{The model}

We follow the modelling structure by CGH. A risk-neutral agency wants to undertake a project with value $V$ and procures it via a second-price sealed-bid auction. $N$ risk-neutral contractors bid for the contract but face uncertainty about the realization of their costs. Ex ante, the costs $C$ are either $c-k_{G}$ with a probability of $(1-q)$ or $c+k_{B}$ with a probability of $q$ where $(1-q)\left(-k_{G}\right)+$ $q k_{B}=0$. All contractors (indexed by $i$ ) have the identical, commonly known cost structure but differ in financial assets $A_{i} . A_{i} \in[0, \infty)$, with a distribution function $f\left(A_{i}\right)$, is private information, that is the agency can neither identify nor quantify the contractors' assets. Due to limited liability, the winning contractor can declare bankruptcy if his costs are higher than the sum of the payment $P_{i}$ and the assets $A_{i}$. In this case the contractor loses all his assets (which are transferred to the agency) but avoids higher losses. ${ }^{7}$ This bankruptcy option makes contractors behave as if they were risk loving, which leads to the result

\footnotetext{
${ }^{7}$ As surety bonds are designed to keep the project in line with the budget and to avoid costly renegotiation, we will not consider the possibility of renegotiation.
} 
that overall (i) contractors bid more aggressively and (ii) contractors that are in a bad financial situation (high bankruptcy rate) ${ }^{8}$ win more often.

If a surety bond of size $L$ is required by the agency, each potential contractor has to have a bond of size $L$ guaranteed by a surety company. Because of the guarantee, the contractor (limited to $A_{i}$ ) and the issuing surety company (limited to $L$ ) are liable. Surety companies are specialized in dealing with the financials of contractors and can - in contrast to the agency - perfectly screen the contractors, that is learn about $A_{i}$. Once a surety company has learned about $A_{i}$, it will charge contractor $i$ a risk-adjusted fee $R_{i}\left(L, A_{i}\right)$, which depends on the size of the bond $L$ and the assets of the contractor $A_{i}$. The fee $R_{i}\left(L, A_{i}\right)$ compensates the surety company for the guarantee either to finish the project or to pay $L$ to the agency in case of the contractor's bankruptcy. In both cases the contractor loses all his assets.

Each surety company can invest $L$ at the risk-free interest rate $r_{0}$. While $\mathrm{CGH}$ assume that a surety company does not accrue interest at the risk-free interest rate if it issues the bond, we relax this assumption because deposits usually accrue interest and the bond is not at risk until the contractor is in financial difficulties, which is the case towards the end of the project. ${ }^{9}$

The investment at the risk-free interest rate renders the timing of the cash flows important. Therefore, we use a two-period model to compare the cash flows at the end of the project. In the first period $(t=0)$, the agency announces the auction, the specifications of the project as well as the required size $L$ of the surety bond. The surety bond is required in $t=1$, so the discounted surety bond that a surety company has to guarantee in $t=0$ is $L /\left(1+r_{0}\right)$. In $t=0$ the surety companies screen the contractors, learn about the value of their financial assets $A_{i} /\left(1+r_{0}\right)$, and charge the discounted fee $R_{i}\left(L, A_{i}\right) /\left(1+r_{0}\right)$, which a contractor has to pay in case of winning the contract. Once the potential contractors have the guarantee, they enter the auction and bid according to their bidding functions. Following the rules of the second-price sealed-bid auction, the lowest bid wins and the winning contractor receives the second lowest bid as the payment. Since we compare all cash flows at the end of the project, we define the bids $P_{i}^{*}\left(A_{i}\right)$ and the payment $P_{i}$ in $t=1$. The discounted payment the winning contractor receives is $P_{i} /\left(1+r_{0}\right)$. Note that $P_{i}$ is uncertain before and during the auction. If a contractor wins, he pays the fee $R_{i}\left(L, A_{i}\right) /\left(1+r_{0}\right)$ to the surety company in $t=0$ and starts the project.

\footnotetext{
${ }^{8}$ As already mentioned, Zheng (2001) shows that if contractors are budget-constrained, the most budget-constrained contractor is the contractor most likely to win the auction.

${ }^{9}$ One might argue that the agency has costs for freezing the deposits. In CGH, these costs are proportional to the size of the bond $L$. We also allow for further costs in a second step in the section "Unfairly priced surety bonds". However, we consider the case in which these costs are either fixed or proportional to the money at risk but not proportional to $L$.
} 
Table 1 The timing of the cash flows

\begin{tabular}{|c|c|c|c|c|c|c|}
\hline \multirow[b]{2}{*}{$\begin{array}{l}\text { Players/ } \\
\text { Time }\end{array}$} & \multicolumn{2}{|c|}{ No bankruptcy } & \multicolumn{2}{|c|}{$\begin{array}{c}\text { Bankruptcy, surety } \\
\text { company finishes }\end{array}$} & \multicolumn{2}{|c|}{$\begin{array}{l}\text { Bankruptcy, } \\
\text { agency finishes }\end{array}$} \\
\hline & $t=0$ & $t=1$ & $t=0$ & $t=1$ & $t=0$ & $t=1$ \\
\hline Agency & $\frac{-P_{i}}{\left(1+r_{0}\right)}$ & V & $\frac{-P_{i}}{\left(1+r_{0}\right)}$ & V & $\frac{-P_{i}}{\left(1+r_{0}\right)}$ & $\begin{array}{l}V-c-k_{B} \\
+\left(A_{i}-R_{i}\left(L, A_{i}\right)\right) \\
+L-C_{B}+P_{i}\end{array}$ \\
\hline \multirow[t]{2}{*}{$\begin{array}{l}\text { Surety } \\
\text { company }\end{array}$} & $\frac{-L_{i}}{\left(1+r_{0}\right)}$ & $L$ & $-\frac{L_{i}}{\left(1+r_{0}\right)}$ & $\begin{array}{l}L-c-k_{B}+P_{i} \\
+\left(A_{i}-R_{i}\left(L, A_{i}\right)\right)\end{array}$ & $-\frac{L_{i}}{\left(1+r_{0}\right)}$ & 0 \\
\hline & $\frac{R_{i}\left(L, A_{i}\right)}{\left(1+r_{0}\right)}$ & & $\frac{R_{i}\left(L, A_{i}\right)}{\left(1+r_{0}\right)}$ & & $\frac{R_{i}\left(L, A_{i}\right)}{\left(1+r_{0}\right)}$ & \\
\hline \multirow[t]{2}{*}{ Contractor } & $\frac{P_{i}}{\left(1+r_{0}\right)}$ & $A_{\mathrm{i}}-C_{\mathrm{i}}$ & $\frac{P_{i}}{\left(1+r_{0}\right)}$ & 0 & $\frac{P_{i}}{\left(1+r_{0}\right)}$ & 0 \\
\hline & $\frac{R_{i}\left(L, A_{i}\right)}{\left(1+r_{0}\right)}$ & & $-\frac{R_{i}\left(L, A_{i}\right)}{\left(1+r_{0}\right)}$ & & $-\frac{R_{i}\left(L, A_{i}\right)}{\left(1+r_{0}\right)}$ & \\
\hline
\end{tabular}

In the last period $(t=1)$, the contractor learns about his true costs and the project is finished either by the contractor, the surety company, or the agency. The bankruptcy decisions and the payoffs in $t=1$ are as follows: if the winning contractor has enough assets, he will finish the project. In this case the guarantee of the surety company is not needed and the utility of the agency is $U=V-P_{i}$. If the costs are high and the winning contractor's assets are not sufficient to finish the project, the winning contractor loses all his assets and the surety company has two options: first, if $A_{i}$ is large enough so that the difference between the costs and the sum of the payment and the remaining assets is smaller than the bond $\left(c+k_{B}-P_{i}-\left(A_{i}-R_{i}\left(L, A_{i}\right)\right) \leqslant L\right)$, the surety company finishes the project. In this case the utility of the agency is again $U=V-P_{i}$. Second, if $A_{i}$ is not large enough so that the difference between the costs and the sum of the payment and the remaining assets is larger than the bond $\left(c+k_{B}-P_{i}-\left(A_{i}-R_{i}\left(L, A_{i}\right)\right)>L\right)$, the surety company pays the bond to the agency. In this case the agency obtains $L$ and the remaining assets of the contractor, which implies that the utility of the agency is given by $U=V-c-k_{B}+\left(A_{i}-R_{i}\left(L, A_{i}\right)\right)+L-C_{B} . C_{B}$ are additional bankruptcy costs of the agency if she finishes the project herself. An overview of the timing of the cash flows is displayed in Table 1. 


\section{Fairly priced surety bonds}

In this section it is assumed that surety companies are risk-neutral profit maximizers, that screening is costless and that the market for surety bonds is perfectly competitive. This implies that surety companies make zero profits. The price of the surety bond for contractor $i$ is then given by the requirement that the surety company is indifferent between issuing the bond and investing into the risk-free asset:

$$
E\left[\Pi_{S}\left(\text { issue }, R_{i}\left(L, A_{i}\right), L\right)\right]=L .
$$

Concerning the bidding in $t=0$, each contractor will take the fee $R_{i}\left(L, A_{i}\right) /$ $\left(1+r_{0}\right)$ and the remaining assets $\left(A_{i}-R_{i}\left(L, A_{i}\right)\right) /\left(1+r_{0}\right)$ into account and bid according to his equilibrium bidding function $P_{i}^{*}\left(A_{i}\right)$. It is well known that if the procurement mechanism is a second-price sealed-bid auction, the equilibrium bid is such that in the case of winning with this payment, the contractor is indifferent between winning and not winning the contract. Therefore,

$$
\Pi_{C}\left(\operatorname{win}, P_{i}=P_{i}^{*}\left(A_{i}\right), R_{i}\left(L, A_{i}\right), L\right)=A_{i} .
$$

As mentioned before, there are three different cases that have to be considered:

(i) The winning contractor has enough assets and never goes bankrupt (contractors of group (i)). In this case $L$ is never at risk. Consequently, the surety company does not need to charge a risk premium $\left(R_{i}\left(L, A_{i}\right)=0\right)$. This result differs from CGH because here the contractor does not have to pay any fee, whereas in CGH even the wealthy contractors of group (i) have to pay $r_{0} L$. According to Eq. (2), the equilibrium bid must satisfy $(1-q)\left(P_{i}^{*}\left(A_{i}\right)-c+k_{G}+A_{i}\right)+q\left(P_{i}^{*}\left(A_{i}\right)-c-k_{B}+A_{i}\right)=A_{i}$, which leads to a bid of $P_{i}^{*}\left(A_{i}\right)=c$ for contractors with $A_{i} \geqslant k_{B}$.

(ii) The second case is that the surety company helps the contractor finish the project in case of high costs (contractors of group (ii)). In this case, the optimal fee is defined by $R_{i}\left(L, A_{i}\right)+(1-q) L+q\left(L-\left(c+k_{B}-E\left[P_{i}\right]-\right.\right.$ $\left.\left.A_{i}+R_{i}\left(L, A_{i}\right)\right)\right)=L .{ }^{10} E\left[P_{i}\right]$ is the expected payment in case of winning and

${ }^{10}$ If this condition holds, the surety company is indifferent between issuing the bond (left-hand side) and not issuing the bond (right-hand side). The left-hand side is given by the fee, the bond (if costs are low), and the amount the surety company has to pay if the costs are high and if it wants to help the contractor finish the project. 
depends on the bids submitted by the other contractors. The last equation translates into a fee of $R_{i}\left(L, A_{i}\right)=q\left(c+k_{B}-E\left[P_{i}\right]-A_{i}\right) /(1-q)$, which also does not depend on the size of $L$, as the surety will never be paid. According to Eq. (2), a contractor bids $P_{i}^{*}\left(A_{i}\right)$ such that $(1-q)$ $\left(P_{i}^{*}\left(A_{i}\right)-c+k_{G}+A_{i}-R_{i}\left(L, A_{i}\right)\right)=A_{i}$, which gives $(1-q) P_{i}^{*}\left(A_{i}\right)+q E\left[P_{i}\right]=c$. Given the payment rule of the second-price sealed-bid auction, the bid must be $P_{i}^{*}\left(A_{i}\right)=c$ if $A_{i} \geqslant k_{B}-(1-q) L .^{11}$

(iii) The third case is that the contractor goes bankrupt and the surety company does not finish the project and pays $L$ to the agency (contractors of group (iii)). Then, the surety company sets $R_{i}\left(L, A_{i}\right)+(1-q) L=L$, which gives $R_{i}\left(L, A_{i}\right)=q L$. The contractors bid such that $(1-q)\left(P_{i}^{*}\left(A_{i}\right)\right.$ $\left.-c+k_{G}+A_{i}-R_{i}\left(L, A_{i}\right)\right)=A_{i}$, which gives $P_{i}^{*}\left(A_{i}\right)=c-k_{G}+q L+A_{i} q /(1-q)$ if $A_{i}<k_{B}-(1-q) L$. Note that $P_{i}^{*}\left(A_{i}\right)<c$. These results are summarized in the following Lemma ${ }^{12}$ :

Lemma 1 The bidding function under fair pricing is given by:

$$
\text { For } L<\frac{k_{B}}{(1-q)} \text { : }
$$

$$
P_{i}^{*}\left(A_{i}, L\right)= \begin{cases}c-k_{G}+q L+\frac{q A_{i}}{(1-q)} & \text { if } 0 \leqslant A_{i}<k_{B}-(1-q) L \\ c & \text { if } A_{i} \geqslant k_{B}-(1-q) L\end{cases}
$$

For $L \geqslant \frac{k_{B}}{(1-q)}$ :

$$
P_{i}^{*}\left(A_{i}, L\right)=c .
$$

\section{The optimal size of the surety bond}

The next step is to determine the optimal size of the surety bond that maximizes the utility of the agency. Assume first that $L<k_{B} /(1-q)$. Expression

\footnotetext{
${ }^{11}$ If a contractor of this group wins, there are two possible payments. First, the payment is determined by a contractor of group (i) with $P_{i}^{*}\left(A_{i}\right)=c$. Second, the payment is determined by a contractor of the same group. With $P_{i}^{*}\left(A_{i}\right)=c$, we have $E\left[P_{i}\right]=c$. As the next paragraph shows, a contractor of group (iii) will always bid less.

12 The corresponding Lemma in CGH is Lemma 4.
} 
(5) represents the expected utility of the agency, where $f_{i}$ denotes the distribution of the $i$ th lowest assets and $A_{2}$ denotes the second lowest asset.

$$
\begin{aligned}
V & -\int_{k_{B}-(1-q) L}^{\infty} c f_{1}(A) d A \\
& -(1-q) \int_{0}^{k_{B}-(1-q) L}\left[\int_{A}^{k_{B}-(1-q) L}\left(c+\frac{q A_{2}}{(1-q)}-k_{G}+q L\right) f_{2}\left(A_{2}\right) d A_{2}\right] f_{1}(A) d A \\
& -(1-q) \int_{0}^{k_{B}-(1-q) L}\left[\int_{k_{B}-(1-q) L}^{\infty} c f_{2}\left(A_{2}\right) d A_{2}\right] f_{1}(A) d A \\
& -q \int_{0}^{k_{B}-(1-q) L}\left(c+k_{B}-(1-q) L-A+C_{B}\right) f_{1}(A) d A .
\end{aligned}
$$

The first integral represents the case in which the winning contractor has assets $(A)$ that are large enough to ensure the completion of the project either by himself or by the surety company. In this case the contractor receives $c$ as payment (groups (i) and (ii)). Concerning the second and third integral, they represent that case in which the project is only finished if the costs are low. The second integral depicts the case in which a contractor of group (iii) wins and receives a bid of a contractor of the same group as the payment. The third integral is the case in which a contractor of group (iii) wins and receives $c$ as the payment. The last integral represents the case when the costs are high and neither the winning contractor nor the surety company finishes the project. Expression (5) can be rewritten as:

$$
\begin{aligned}
V-c-q \int_{0}^{k_{B}-(1-q) L}\left(k_{B}-(1-q) L\right. & \left.-A+C_{B}\right) f_{1}(A) d A \\
- & (1-q) \int_{0}^{k_{B}-(1-q) L}\left[\int_{A}^{k_{B}-(1-q) L}\right. \\
& \left.\left(\frac{q A_{2}}{(1-q)}-k_{G}+q L\right) f_{2}\left(A_{2}\right) d A_{2}\right] f_{1}(A) d A .
\end{aligned}
$$

In the case of $L \geqslant k_{B} /(1-q)$ the surety bond is such that the project will always be finished (only group (i) and (ii) contractors). The utility of the agency is then given by:

$$
V-c \text {. }
$$

The optimal size of the surety bond is determined by optimizing (6) and (7) with respect to $L$. 
Proposition 1 The optimal size of the surety bond that maximizes the agency's utility is $L^{*} \geqslant k_{B} /(1-q)$.

Proof Note that the integrand of the first integral in Eq. (6) is positive because $A<k_{B}-(1-q) L$. For the same reason, the integrand of the second integral is positive as well. As both integrals are subtracted from $V$, Eq. (6) is maximized if the range of each integral becomes zero. This is the case for $L^{*}=k_{B} /(1-q)$ (or larger as then expression (7) applies).

From Lemma 1 we know that for $L \geqslant k_{B} /(1-q)$, the surety company will always complete the project for any $A_{i}$, which yields a utility of $V-c$ for the agency. This result is contrary to CGH where it can be optimal that the project is not completed by the surety company. In line with the insurance literature, it holds that fair insurance pricing leads to an efficient outcome in the sense that the surety company always finishes the project. Interestingly, this can be obtained with overinsurance, in the sense that the required surety bond $L$ might be larger than the money at risk. However, overinsurance on the side of the agency translates into full insurance on the side of the surety company as this implies that the surety company will always finish the project.

The interpretation of this result carries over to the U.S. practice of surety bonds in which the agency requires a bond that is equal to the actual payment, that is $L=E[P]$. In this case CGH come to the conclusion that inefficient overinsurance may arise. Proposition 1 shows that even if there is overinsurance, this is efficient as long as the surety bond is priced fairly. On the other hand, the U.S. practice might lead to underinsurance. The expected payment $E[P]$ under fair pricing is always lower than or equal to $c$, the expected costs of the project. Now, if $c$ is smaller than $k_{B} /(1-q)$, then the surety will be too small. In other words, if variations in costs are potentially large, then requiring a surety of the size of the expected costs might provide too little cover. $^{13}$

\section{Unfairly priced surety bonds}

Having established that for fair premia full insurance (and even overinsurance) can be optimal, let us now consider the case in which the surety company faces costs of screening and risk taking that might be a reason for unfair insurance premia. As it is common in the insurance literature, ${ }^{14}$ we assume that the unfair

\footnotetext{
${ }^{13}$ We thank a referee for pointing this out to us.

${ }^{14}$ See for example Gollier (2000, p. 101).
} 
part of the premium consists of a fixed fee $\mu$ (e.g., for the fixed screening costs) and a premium loading $\lambda$, which is proportional to the actuarial value of the policy. The fee contractor $i$ has to pay is equal to $R_{i}\left(L, A_{i}\right)=\mu+(1+\lambda) R_{i}^{f}\left(L, A_{i}\right)$, where $R_{i}^{f}\left(L, A_{i}\right)$ is the fair premium derived in the previous section. We begin with the simpler case of $\lambda=0$.

\section{Surety bonds with a fixed fee}

If screening costs are positive but constant, that is they do not depend on the size of the bond, the premium a surety company demands in a competitive market is $R_{i}\left(L, A_{i}\right)=\mu+R_{i}^{f}\left(L, A_{i}\right)$, where $\mu$ is the fixed fee. That is, the risk loading $\lambda$ is set equal to zero.

Every bidder has to pay $\mu$ in addition to the fair premium in case of winning the contract. Thus the fixed fee $\mu$ has the same effect as an increase in the cost term $c$ by $\mu$. Therefore the analysis of the previous section goes through in this case as well, with the only difference that $c$ has to be replaced by $c+\mu$ in every expression. This implies that in expression (5), the term $\mu$ has to be subtracted. Hence, if the agency decides to demand a surety such that every contractor has to pay $\mu$ in case of winning the contract, the optimization problem remains unchanged. The agency thus decides to choose $L \geqslant k_{B} /(1-q)$. The utility of the agency is then given by

$$
V-c-\mu
$$

Now if $\mu$ is small, the results of the previous section continue to hold. However, if $\mu$ is large (e.g., $\mu \geqslant V-c$ ), the agency might decide either not to insure herself at all (if the bankruptcy costs are small), or to abandon the project. We summarize this result in the following proposition.

Proposition 2 Let $\lambda=0$ and $\mu>0$. Then, if $\mu$ is small $L^{*} \geqslant k_{B} /(1-q)$ is optimal. If $\mu$ is large, either $L^{*}=0$ or the project is abandoned.

Thus full insurance is still optimal for small values of $\mu$.

\section{Surety bonds with a risk loading}

Now the general case in which $\lambda>0$ is considered. We proceed as follows: in a first step, we derive the bidding strategies of the contractors. The optimal size of the bond is discussed next.

Interestingly, if a risk loading is imposed on the price for the surety bond, then the bidding behaviour of the contractors might become non-monotonic or even decrease in wealth. 
Proposition 3 If $L<k_{B} /(1-q)$ and $\lambda>0$, the bidding function is non-monotonic. If $L \geqslant k_{B} /(1-q)$ and $\lambda>0$, the bidding function decreases in wealth.

Proof Following steps (i)-(iii) from above, the bids of the contractors are as follows: in case (i), the contractor never goes bankrupt. Therefore, the surety company will only charge the fixed premium $R_{i}\left(A_{i}\right)=\mu$ and the bid will be equal to $P_{i}^{*}\left(A_{i}\right)=c+\mu$ if $A_{i} \geqslant k_{B}$.

In case (iii) the surety company pays $L$ to the agency if the costs are high, that is it will not help the contractor finish the project. Therefore, the surety company will charge a premium of $R_{i}\left(A_{i}\right)=q L(1+\lambda)+\mu$ because it wants to be compensated for paying $L$ to the agency in case the costs are high, which occurs with probability $q$. The bids of the contractors in group (iii) have to satisfy $(1-q)\left(P_{i}^{*}\left(A_{i}\right)-c+k_{G}+A_{i}-R_{i}\left(A_{i}\right)\right)=A_{i}$, which gives $P_{i}^{*}\left(A_{i}\right)=c+\mu-k_{G}+q A_{i} /$ $(1-q)+q L(1+\lambda)$. A property of this bidding function is that it increasing in $A_{i}$. Therefore, the highest bid of group (iii) is placed by the contractor with the highest $A_{i}$ in this group.

In case (ii) the surety company helps the contractor to complete the project and charges a premium of $R_{i}\left(A_{i}\right)=\mu+q(1+\lambda)\left(c+k_{B}-E\left[P_{i}\right]-A_{i}+R_{i}\left(A_{i}\right)\right)$. Here the premium compensates the surety company for the case in which the costs are higher than the expected payment and the remaining assets (but lower than $L){ }^{15}$ This implies a fee of $R_{i}\left(A_{i}\right)=\left(\mu+q(1+\lambda)\left(c+k_{B}-E\left[P_{i}\right]-A_{i}\right)\right) /(1-q(1+\lambda))$. The bids of the contractors have to satisfy $(1-q)\left(P_{i} *\left(A_{i}\right)-c+k_{G}+A_{i}-\right.$ $\left.R_{i}\left(A_{i}\right)\right)=A_{i}$. The solution to this problem is $P_{i}^{*}\left(A_{i}\right)=(1-q-q \lambda)+q E\left[P_{i}\right](1+\lambda)=$ $c+\mu+q \lambda\left(k_{B}-A_{i}\right) /(1-q)$, which depends on the bidding function $P_{i}^{*}\left(A_{i}\right)$ and on the expected payment $E\left[P_{i}\right]$ if a contractor wins with $P_{i}^{*}\left(A_{i}\right)$. A property of this bidding function is that the bid is decreasing in $A_{i}$ as $E\left[P_{i}\right]$ is increasing in $P_{i}^{*}\left(A_{i}\right)$. Therefore, the highest bid of group (ii) is placed by the contractor with the lowest $A_{i}$ of this group.

Now, we turn to the question which contractors belong to groups (ii) and (iii). To do so, we have to identify the marginal contractor with the lowest $A_{i}=\hat{A}_{i}$ the surety company is willing to help, that is the contractor with the lowest assets who still belongs to group (ii). First, assume that the highest bid of group (ii) is always higher than the highest bid of group (iii). If the contractor with the highest bid of group (ii) wins, the payment must be the same as his bid for it is the maximum possible bid. In this case $P_{i}^{*}\left(\hat{A}_{i}\right)=E\left[P_{i}\right]$ and thus the bid is $P_{i}^{*}\left(\hat{A}_{i}\right)=c+\mu+\left(q \lambda\left(k_{B}-\hat{A}_{i}\right) /(1-q)\right.$. Hence, the marginal contractor the surety company helps to finish the project is the contractor with

${ }^{15} E\left[P_{i}\right]$ is again the expected payment in equilibrium if a contractor with assets $A_{i}$ wins, that is the expectation of the second lowest bid under the assumption that $P_{i}^{*}\left(A_{i}\right)$ is the lowest bid. 
$\hat{A}_{i}=k_{B}-(1-q) L$. Second, we have to show that the surety company does not want to finish the project and prefers paying the bond to the agency for contractors with $A_{i}<k_{B}-(1-q) L$, namely $L-\left(c+k_{B}-P-\left(A_{i}-R_{i}\left(A_{i}\right)\right)\right)<0$. Substituting the fee and the maximum possible payment (since it is the best case for the surety company if a contractor of group (iii) wins), the surety company indeed does not help contractors with $A_{i}<k_{B}-(1-q) L$ to finish the project. Note that our assumption that the maximum possible bid is placed by a contractor of group (ii) holds for $\hat{A}_{i}=k_{B}-(1-q) L$, because the bids of all contractors with assets below $\hat{A}_{i}$ (group (iii)) lie below the maximum possible bid and the contractor with $\hat{A}_{i}$ also bids more than $c+\mu$. If $L \geqslant k_{B} /(1-q)$, group (iii) ceases to exist, so that the bidding function becomes decreasing in wealth (for contractors of group (ii)) and then constant (for contractors of group (i)).

The non-monotonic bidding function (for low values of $L$ ) has implications for the final allocation. The intermediate group of contractors, that is those who might go bankrupt and for which the surety company finishes the project in case of bankruptcy, place the highest bid. Thus the agency is more likely to end up either with those contractors who never go bankrupt or with those for whom the surety company pays the bond in case of bankruptcy.

If the surety is large enough, then this intermediate group is made up of all bidders with low assets. This implies that the lowest bids will be placed by those contractors with the largest assets, that is with the lowest probability of going bankrupt. Hence, a large enough surety will prevent ALTs. If the surety is smaller, then the problem of ALTs will at least be alleviated to some extent. This is different from the result in CGH. In their setup, the lowest bids always come from the contractors with the lowest wealth and thus with the highest risk of bankruptcy. Hence, the difference in pricing matters in this context. If pricing is proportional to the money at risk, high-risk contractors have to pay more to the surety company and thus become less competitive in the market. If pricing is proportional to the size of the bond, all contractors pay the same unfair part of the premium, which implies that the surety company does not help in separating out the more risky contractors.

The bidding functions for the non-monotonic case are depicted in Figure 1. The solid line sketches the bidding function and the dashed line gives an approximation of the real bidding function for $E\left[P_{i}\right]=P_{i}^{*}\left(A_{i}\right)$, which yields $P_{i}^{*}\left(A_{i}\right)=c+\mu+q \lambda\left(k_{B}-A_{i}\right) /(1-q)$. Note that the real bidding function has to be below the approximation because a winning contractor receives some kind of average payment and not his bid that would be the minimum possible payment.

The dotted line in Figure 1 depicts the bidding function for the case in which the risk loading is zero $(\lambda=0)$. The bidding function is increasing in $A_{i}$ until it reaches its maximum $(c+\mu)$ at $A_{i}=k_{B}-(1-q) L$ and is constant afterwards. 


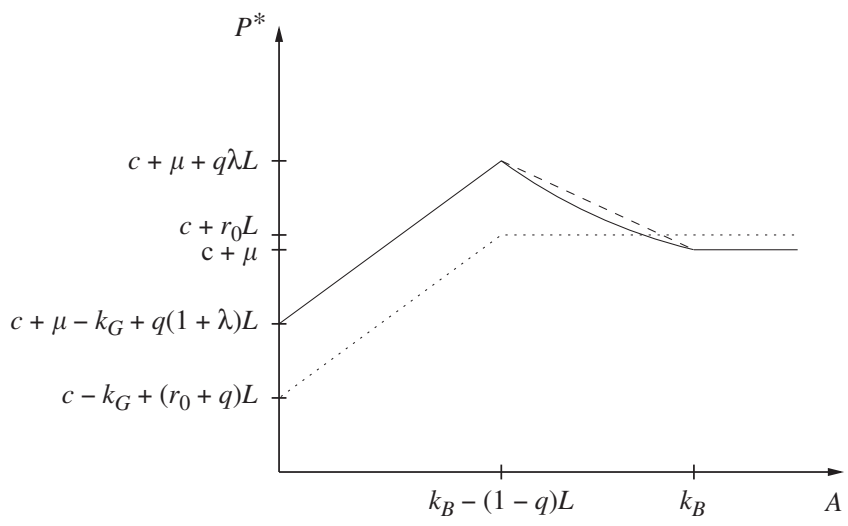

Figure 1. Bidding function for unfair premia; $\lambda>0$ : solid line; $\lambda=0$ : dotted line.

If $\lambda>0$, the bidding function (the solid line) first increases in $A_{i}$ until it reaches its maximum $(c+\mu+q \lambda L)$ at $A_{i}=k_{B}-(1-q) L$, then decreases in $A_{i}$ to $c+\mu$ at $A_{i}=k_{B}$ and is constant afterwards. We have not been able to solve for the optimal size of the surety bond analytically in this case. However, if the costs of bankruptcy for the agency are high and the agency thus wants to set the probability of non-fulfilment to zero, she should require a large surety bond, $L^{*} \geqslant k_{B} /(1-q)$. Then, $L^{*}$ is such that the winning contractor or the surety company always finishes the project. This result is in contrast to the standard insurance literature, where only partial insurance will be demanded if insurance is priced marginally unfair.

Moreover, also in the pricing structure analysed in $\mathrm{CGH}, L^{*}=k_{B} / 1-q$ might be optimal if bankruptcy costs are large. However, $L^{*}>k_{B} / 1-q$ never holds in their model. Overinsurance might be optimal in our case because it does not come at additional costs if the loading is proportional to the money at risk, and not, as in $\mathrm{CGH}$, proportional to the size of the surety bond. This has implications for the U.S. practice where a surety bond of the expected size of the project (approximately $L=E[P]$ ) is required. Even if this implies overinsurance, as $\mathrm{CGH}$ argue, it might still be optimal under unfair pricing.

\section{Conclusion}

Industries with uncertainty about future costs are plagued by ALTs and bankruptcy. In many countries compulsory surety bonds are used to deal with this problem. CGH (2004) show that surety bonds indeed mitigate the problem of ALTs. CGH assume that the cost of the surety bond are proportional to its size. We modify their framework and assume in a first step that surety bonds 
are priced fairly - the common benchmark case in the insurance literature. Then, in contrast to $\mathrm{CHG}$, the problem becomes analytically solvable and full insurance or even overinsurance is optimal, that is the project is always finished either by the contractor or by the surety company. In a second step, we introduce a risk loading (unfair premia) and show that full insurance or even overinsurance might still be optimal. This result is interesting to note as usually in the insurance literature marginally unfair premia lead to partial insurance.

If the unfairly priced surety bond is large enough to cover all costs in all cases, the contractors' bids decrease in wealth. Potential contractors with low wealth have to pay a high risk premium and thus submit higher bids compared to contractors with larger wealth. Thus surety bonds with costs that are proportional to the money at risk might help to avoid ALTs in the sense that contractors with a higher risk of bankruptcy will not bid less than a contractor with a lower risk of bankruptcy.

The analysis has implications for the U.S. practice where a surety bond of the expected size of the project is usually required. Even if this implies overinsurance, as CGH argue, the U.S. practice might still be optimal under unfair pricing as long as the unfair part of the premium is proportional to the money at risk and not to the size of the surety bond.

\section{Acknowledgements}

We thank Esther Hauk and two anonymous referees for helpful comments.

\section{References}

Board, S. (2007) 'Bidding into the red: A model of post auction bankruptcy', Journal of Finance 62: 2695-2723.

Calveras, A., Ganuza, J.J. and Hauk, E. (2004) 'Wild bids. Gambling for resurrection in procurement contracts', Journal of Regulatory Economics 26: 41-68.

Engel, A., Ganuza, J.J., Hauk, E. and Wambach, A. (2006) 'Managing risky bids', in N. Dimitri, G. Piga and G. Spagnolo (eds) Handbook of Procurement, Cambridge, UK: Cambridge University Press.

Engel, A. and Wambach, A. (2006) 'Public procurement under limited liability', Rivista di Politica Economia 96: 13-40, Reprinted in Piga, G. and Thai, K. (eds) (2007) The Economics of Public Procurement, Palgrave MacMillan.

European Commission Enterprise Section (1999) 'Abnormally Low Tenders', from http:// ec.europa.eu/enterprise/construction/alo/tender.htm.

Gollier, C. (2000) 'Optimal insurance design: What can we do with and without expected utility', in G. Dionne (ed) Handbook of Insurance, Boston: Kluwer Academic Publishers.

Parlane, S. (2003) 'Procurement contracts under limited liability', The Economic and Social Review 34: $1-21$.

Ramsey, M. (2008) Surety Market Report, Surety Information Office, www.sio.org.

Russell, J.S. (1999) Surety Bonds for Construction Contracts, Russel, VA: ASCE Publications.

White, M.J. (1989) 'The corporate bankruptcy decision', Journal of Economic Perspectives 3: 129-151.

Zheng, C.Z. (2001) 'High bids and broke winners', Journal of Economic Theory 100: 129-171. 